\title{
Teaching Methodology for the Training of a Laparoscopic Technique: Intestinal Anastomosis
}

\author{
José Luis Ruiz-Gómez ${ }^{1 *}$, Roberto Fernández Santiago' ${ }^{1}$ Antonio López Useros ${ }^{1}$, \\ Carlos Redondo-Figuero' ${ }^{2}$, José C. Manuel-Palazuelos ${ }^{3}$ \\ ${ }^{1}$ Instructor General Surgery, Hospital Virtual Valdecilla, Santander, Spain \\ ${ }^{2}$ Medical and Chirurgical Science, University of Cantabria, Santander, Spain \\ ${ }^{3}$ Hospital Virtual Valdecilla, Santander, Spain \\ Email: *jolurcg@gmail.com
}

How to cite this paper: Ruiz-Gómez, J.L., Santiago, R.F., Useros, A.L., Redondo-Figuero, C. and Manuel-Palazuelos, J.C. (2017) Teaching Methodology for the Training of a Laparoscopic Technique: Intestinal Anastomosis. Surgical Science, 8, 384-401.

https://doi.org/10.4236/ss.2017.88042

Received: June 26, 2017

Accepted: August 21, 2017

Published: August 24, 2017

Copyright (๑) 2017 by authors and Scientific Research Publishing Inc. This work is licensed under the Creative Commons Attribution International License (CC BY 4.0).

http://creativecommons.org/licenses/by/4.0/

\begin{abstract}
Traditionally surgeons learned surgical techniques by training them directly in the patient by imitating the actions of the surgeon with more experience. Today this methodology is difficult to apply, since there are multiple factors that hinder its use. The limited time of training systems, scarcity of resources, patient safety or the need to learn new techniques of minimally invasive surgery, make the training of surgeons require a different learning methodology. This study has designed a new methodology for the learning of surgical techniques that minimizes the impact of all the previous factors on the training of surgeons. Its effectiveness in the teaching of laparoscopic manual intestinal anastomosis is analyzed. It has been asked a group of 24 expert surgeons teaching in intestinal anastomoses, which are the steps that must include the teaching of the technique. The phases evaluated with the highest score were included in the methodology. Once the steps of the methodology were designed, 25 general surgeons were chosen and divided into three groups according to their level of experience (experts, trained and beginners). Each participant performed five training sessions following the new methodology. The technical quality of the anastomosis, the overall development of the operation, as well as the feedback developed between the participants and the instructor was analyzed. After analyzing the results it was observed that structured feedback between the instructor and the participant increases the involvement of the participant in the learning process and reduces the time needed to acquire the competence. With this methodology the inexperienced participants perform the fifth anastomosis with quality parameters close to those obtained by the expert participants. In addition, this methodology allows to individualize the learning according to the needs of each participant.
\end{abstract}




\section{Keywords}

Methodology, Learn, Surgery, Anastomosis, Intestinal

\section{Introduction}

The teaching of the exercise of surgery has varied little over the years. Surgeons learned surgical techniques directly from the patient by imitating the actions of the master surgeon. This methodology has formed excellent surgeons during the last years, but the society is progressing and it is necessary to adapt to the changes. The training of surgeons must also evolve [1].

At present social changes make it difficult to use the traditional methodology. Thus training systems are limited in time so there may be surgical techniques that are not sufficiently trained. In addition, surgical learners must learn traditional techniques plus new minimally invasive surgery techniques. The use of surgical time to perform the teaching increases the price of the procedure, so the pressure to reduce expenses to the detriment of teaching. Another important aspect is the safety of the patient, who wants to be operated by a surgeon who has completed his learning curve. All these social changes make the training of surgeons require a different teaching methodology [2].

Nowadays, surgical techniques can be learned in the simulation labs, away from the patient and from the real operating theater. Surgical apprentices can repeat training sessions as often as necessary to achieve mastery. The laparoscopic skills acquired through the simulation are transferred to the operating room with real patients [3] [4] [5].

It has been proven that the use of feedback by an expert instructor is superior to other forms of learning because it decreases the time necessary to perform the practice and the number of sessions necessary to acquire the competence [6] [7].

This study has designed a new methodology for the learning of surgical techniques that minimizes the impact of all the previous factors on the training of surgeons. This methodology is implemented in the simulation laboratory. The feedback between the instructor and the student is one of its most important phases. Its effectiveness in the teaching of laparoscopic manual intestinal anastomosis is analyzed.

\section{Materials and Methods}

\subsection{Reporting Method}

This was an observational study that evaluated simulation for educational use. Reporting follows the guidelines to Strengthening the Reporting of Observational Studies in Epidemiology (STROBE) and key elements to report for simulation-based research both published in this journal and other major simulation journals [8]. 


\subsection{Study Design}

This is a prospective study of a single cohort in which a group of surgeons and teachers in intestinal anastomoses have been asked which is the most important phases that should include the teaching of the technique. The Delphi methodology has been used. In most studies using this methodology the number of expert participants is usually between 15 and 20 .

We selected 30 digestive surgeons who had performed more than 150 advanced laparoscopic procedures, more than 20 laparoscopic intestinal anastomosises and had more than 10 years of surgical experience. They belonged to 20 hospitals throughout the country and they had no direct relationship with the Virtual Hospital Valdecilla. Their participation was voluntary and unpaid. 6 surgeons did not respond to the Delphi survey so they were excluded from the study.

The Delphi methodology was used and 24 questions were asked about all phases of anastomosis teaching, from technical questions about the procedure, theoretical knowledge of the participants, their psychological state or questions related to teaching, as the experience of the instructor, model or training simulator employed. They were also asked about the technical steps of the anastomosis and the quality parameters to be met. All questions were rated with a score of 0 to 5 , where 0 equals a question of null importance for the realization of the practice and 5 a question of maximum importance. We analyzed the answers obtained and included in the new methodology the questions that the experts rated with the highest score (Table 1 ).

The new methodology includes the following phases: 1) Provision of bibliographical and visual material to the students about the technique to be trained. 2) Introduction to simulation to create an attractive learning environment. 3) Demonstration of the critical steps of the technique by the instructor. 4) Demonstration of adequate ergonomics in front of the endotrainer. 5) Manipulation of the laparoscopic instruments, realization of the technique by the student and structured feedback with the instructor. 6) Evaluation of the learning session in accordance with the established objectives and measurement of the time spent in performing the technique. 7) Debriefing to reflect on the learning experience. 8) Repetition of the training sessions with the improvement objectives analyzed in the debriefing until the student obtains the competence (Table 2).

\subsection{Setting}

The study took place at Valdecilla Virtual Hospital, a healthcare simulation center located in the city of Santander, Cantabria, Spain. This center of innovation was created through a consortium between the University of Cantabria, the Cantabrian Government, and the Marques of Valdecilla University Hospital. It is an Accredited Educational Institution by the American College of Surgeons.

The sessions were developed in the simulation laboratory, using an ex-vivo model, specifically terminal ileum of porcine origin sacrificed in the twenty-four hours prior to the practice. 
Table 1. Questionnaire sent to experts. Rate the following variables that may influence the performance of a laparoscopic laterallateral entero-lateral anastomosis in physical simulator, according to the importance they have for you, with a numerical score of 1 to 5 , being 1 a variable without importance and 5 a very important variable for the accomplishment of the anastomosis.

QUESTION 1-Do you consider important that the apprentice has theoretical knowledge regarding the anastomosis before the practice? $\begin{array}{llllll}0 & 1 & 2 & 3 & 4 & 5\end{array}$

QUESTION 2-Are the environmental conditions of the room (temperature, humidity, silence...) important for performing the anastomosis?

$\begin{array}{llllll}0 & 1 & 2 & 3 & 4 & 5\end{array}$

QUESTION 3-The psychological state of the learner: hours of sleep the night before, release of guard, situation of emotional stress due to personal problems or work. Does this influence the performance of the anastomosis?

$\begin{array}{llllll}0 & 1 & 2 & 3 & 4 & 5\end{array}$

QUESTION 4-In your opinion, is the instructor's teaching experience important?

$\begin{array}{llllll}0 & 1 & 2 & 3 & 4 & 5\end{array}$

QUESTION 5-And clinical experience?

$\begin{array}{llllll}0 & 1 & 2 & 3 & 4 & 5\end{array}$

QUESTION 6-Is it important the coordination between the members of the team for the accomplishment of this practice?

$\begin{array}{llllll}0 & 1 & 2 & 3 & 4 & 5\end{array}$

QUESTION 7-Do you think that the physical simulator model can be important to perform this type of intestinal anastomosis?

$\begin{array}{llllll}0 & 1 & 2 & 3 & 4 & 5\end{array}$

QUESTION 8-Do you think that the type of organic material used to perform the anastomosis is important: "ex vivo viscera" frozen "ex vivo" fresh?

$\begin{array}{llllll}0 & 1 & 2 & 3 & 4 & 5\end{array}$

QUESTION 9-The ergonomics: height of the simulator and the monitor regarding the height of the learner, learner body position ... is it important in the performance of the practice?

$\begin{array}{llllll}0 & 1 & 2 & 3 & 4 & 5\end{array}$

QUESTION 10-How much do you think the instruments influence the correct anastomosis?

$\begin{array}{llllll}0 & 1 & 2 & 3 & 4 & 5\end{array}$

QUESTION 11-Do you think that the orientation of the anastomosis in horizontal or vertical can influence for a better realization of the same?

$\begin{array}{llllll}0 & 1 & 2 & 3 & 4 & 5\end{array}$

QUESTION 12-Do you believe that the material used in the suture determines that the anastomosis is done properly?

$\begin{array}{llllll}0 & 1 & 2 & 3 & 4 & 5\end{array}$

QUESTION 13-Is it important to perform a posterior sero-serous suture to make the anastomosis of good quality?

$\begin{array}{llllll}0 & 1 & 2 & 3 & 4 & 5\end{array}$

QUESTION 14-Do you consider important how to open the intestine, with scissors, electric scalpel or ultrasound?

$\begin{array}{llllll}0 & 1 & 2 & 3 & 4 & 5\end{array}$

QUESTION 15-Do you think it is important where to start suturing the anastomosis (Angle, back half face) ?

$\begin{array}{llllll}0 & 1 & 2 & 3 & 4 & 5\end{array}$

QUESTION 16-The type of suture: continuous, loose points, total points, extramucosal points, is it important in performing the anastomosis?

$\begin{array}{llllll}0 & 1 & 2 & 3 & 4 & 5\end{array}$

QUESTION 17-Is it important in the execution of the anastomosis to give specific points in the angles, such as Connell?

$\begin{array}{llllll}0 & 1 & 2 & 3 & 4 & 5\end{array}$

QUESTION 18-Do you think it is important to give a serosal reinforcement on the anterior aspect of the anastomosis?

$\begin{array}{llllll}0 & 1 & 2 & 3 & 4 & 5\end{array}$

QUESTION 19-Is important the tension of the suture?

$\begin{array}{llllll}0 & 1 & 2 & 3 & 4 & 5\end{array}$

QUESTION 20-Do you think that the distance between the points can determine that the anastomosis is dehiscent?

$\begin{array}{llllll}0 & 1 & 2 & 3 & 4 & 5\end{array}$

QUESTION 21-Do you believe that the eversion of the edges can determine that the anastomosis has a leak of content?

$\begin{array}{llllll}0 & 1 & 2 & 3 & 4 & 5\end{array}$

QUESTION 22-Do you think is important the time in the execution of the anastomosis?

$\begin{array}{llllll}0 & 1 & 2 & 3 & 4 & 5\end{array}$

QUESTION 23-Is important the realization of feedback between the student and the instructor?

$\begin{array}{llllll}0 & 1 & 2 & 3 & 4 & 5\end{array}$

QUESTION 24-Do you consider that, in addition to visual inspection, it is important that a method of checking the leakage of the anastomosis is applied?

$\begin{array}{llllll}0 & 1 & 2 & 3 & 4 & 5\end{array}$ 
Table 2. Stages of the new training method Stages of the new NMEHQ training method.

\begin{tabular}{cc}
\hline STAGE & CONTENTS \\
\hline 1 & Bibliography and preprocess videos that show the surgical technique \\
2 & Pre-simulation meeting to make contact with the simulation laboratory \\
3 & Discussion of articles and review of procedure \\
4 & Critical steps of the surgical technique demonstrated by the instructor \\
5 & Physical manipulation of laparoscopic instruments \\
6 & Feedback \\
7 & Control of time and quality \\
8 & Rigorous reflection upon completion (debriefing) \\
9 & Deliberate and repetitive practice \\
\hline
\end{tabular}

As pelvitrainer we use the model Szabo-Berci-Sackier (Laparoscopic Trainer Karl Storz, Tuttingen, Alemania). Each participant performed five training sessions. All the anastomosis was recorded in video, without being able to identify the author. The study was conducted between November 2014 and December 2016.

\subsection{Participants}

The study population consisted of surgeons (senior doctors and residents) from surgical specialties working in Valdecilla and Sierrallana hospitals (the first one is a university hospital and the last is a smaller regional hospital). They were divided into three groups A) Beginners: Formed by 10 first-year surgical residents with no previous experience B) Trained: formed by 10 residents of the fourth and fifth year of general surgery who had performed more than 20 intestinal anastomosis in simulation C) Experts: Formed by 5 surgeons with extensive experience in advanced laparoscopic surgery and who had carried out at least 20 intestinal anastomosis in the clinic. All participants completed all 5 practice sessions and none were excluded from the study.

\subsection{Variables}

Epidemiological variables of the participants were age, sex, previous experience in intestinal anastomosis, both open and laparoscopic, level of training and dominant hand.

The type of surgical procedure of the intestinal anastomosis was also defined with the opinions of the experts. All the anastomosis was performed with the same technique that was shown in the video. It was started with a suture with loose stitches of $4 / 0$ silk along $5 \mathrm{~cm}$. The two intestines were then opened and started with a $4 / 0$ monofilament suture in the middle of the posterior face, advancing towards one end, closing the angle with Connell points, and advancing to the middle of the anterior face. With another thread of the same material it was begun by the posterior face next to the previous knot, advancing towards the angle, ending in the anterior face and knotting with the first thread. 


\subsection{Outcome Measures}

Before beginning the learning sessions, the participants' level of theoretical knowledge about intestinal anastomosis was evaluated. To this end, a multiple-choice test is performed with ten questions about theoretical and practical concepts about anastomosis technique.

All teaching sessions were given by the same instructor and evaluated by two surgeon experts in teaching intestinal anastomosis who did not know the participant's identity. The technical quality of the anastomosis was evaluated, taking into account the length of the anastomosis, the eversion of the mucosal borders, the tension of the suture, the distance between the points and the existence of leakage of the anastomosis when subjected to tests of pressure (Table 3).

Both evaluators also visualized the video of the anastomosis and assessed the overall development of the procedure (TGRS) using the validated tool for this technical ability by Martín et al. [9]. Through this tool, the care of the tissues, the development of the operation, the time and the movement, the level of independence of the participant as well as their skills of suture and knotting are valued on a continuous scale (Table 4).

Also at the end of the practice, the participant and the instructor completed a survey about the feedback developed between them throughout the practice. There is no feedback assessment tool for the teaching of intestinal anastomosis, so a similar one was used in the educational field that values the feedback during the learning process from the point of view of the participant and the instructor. This rating has a maximum score of 5 . The technical accomplishment of the anastomosis was timed (Table 5).

\subsection{Statistics}

Means, median, standard deviation (SD), and interquartile range were employed for numerical variables. In addition, the method of Wilson was used to determine CIs and percentages for qualitative variables, while the Mann-Whitney U test was utilized to compare medians. The learning curve of each trainee was determined by using the time of the procedures along with polynomial regression and was adjusted to the fifth degree. To obtain a graphical representation of the four learning curves, locally weighted scatterplot smoothing (LOWESS) was used. LOWESS utilizes multiple regression models that enable smoothing of the data. Each point along the regression curve was produced by a weighted linear least-squares regression to fit the data in the neighbourhood of the local point, with the weights declining as $\mathrm{x}$ values moved farther from the $\mathrm{x}$ value of the local point. R program (R Foundation for Statistical Computing, Vienna, Austria) was used for all statistical analyses [10]; we applied package car for nonparametric regression. $\mathrm{p}<0.05$ was considered statistically significant.

\subsection{Institutional Review Board (IRB) Approval}

The study protocol was approved by the Ethics and Research Committee of the 
Table 3. Assessment of anastomosis.

\section{ANASTOMOSIS ASSESMENT SHEET}

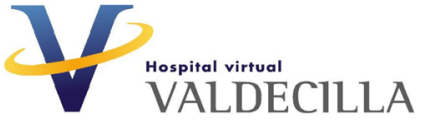

\section{ANASTOMOSIS \\ ASSESSMENT}
[1] Identification number

[2] Date (dd/mm/yyyy):

\section{INSTRUCTOR}

[3] Name

[4] Has he/she previously instructed the student?

1. No

2. Yes

\section{STUDENT}

[5] Name

[6] Sex

1. Male

2. Female

[7]Level of surgical experience

1. BE ("Beginners")

2. TRA ("Trained")

3. EX ("Experts")

[8] Hours of sleep

$$
\mathrm{h}-\min
$$

[9] Outgoingfromduty

1. No

2. Yes

[10] Laterality

1. Right handed

2. Left handed

3. Ambidextrous

[11-12] Anastomosis (ANT) Prior surgicalexperience $\mathrm{N}^{\circ}$ of ANT with open surgery[11]

$\mathrm{N}^{\circ}$ of ANT withlaparoscopic[12]

\section{SURGERY}

[13] Type of anastomosis

1. Entero-enteric

2. Gastroenteric

3. Ileocolic

[14] Type of simulation

1. Table

2. Endotrainer

3. Animal (laparoscopic)

4. Animal (laparotomy)
[15] Optical instruments

1. $0^{\circ}$

2. $30^{\circ}$

[16] Instrumental. Needle holder

1. Curved

2. Straight

[17] Instrumental. Instruments

1. Dissector

2. Clinch

\section{QUALITY OF THE ANASTOMOSIS}

[18] Size (mm)

[19] Everted edges

1. No

2. Yes

[20] Suture tension

1. Loose

2. Appropriate

3. Tense
[21-24] Distance between points

1. Limited $(\leq 2.5 \mathrm{~mm})$

2. Adequated (2.6-3.4)

3. Excessive $(\geq 3.5)$

[25] Existence of leakage

1. No

2. Yes 
Table 4. Assessment of anastomosis (2).

ANASTOMOSIS ASSESMENT SHEET

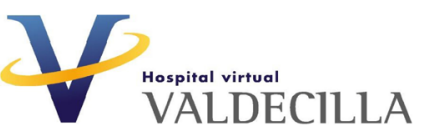

\section{ANASTOMOSIS ASSESSMENT}

( $\mathrm{HVV}$
[1] Identification number

\section{Global Rating Seal of Operative Performance}

\begin{tabular}{|c|c|}
\hline $\begin{array}{l}\text { [26]Tissue care } \\
\text { 1. Frequently causes damage due to misuse of instruments. } \\
\text { 3. Handles tissues carefully although occasionally causes damage. } \\
\text { 5. Handle tissues carefully without causing damage. } \\
\text { 1----+----2----+-----3-----+----4---+---5 }\end{array}$ & $\mathrm{A}=$ \\
\hline $\begin{array}{l}\text { [27]Development of the procedure } \\
\text { 1. Frequently interrupts the procedure or needs to ask the next step. } \\
\text { 3.Know the steps but plan the procedure step by step and not globally. } \\
\text { 5. The course of the procedure is planned and moves effortlessly. } \\
\text { 1----+----2----+-----3-----+----4----+----5 }\end{array}$ & $\mathrm{B}=$ \\
\hline $\begin{array}{l}\text { [28]Time and movement } \\
\text { 1.Many unnecessary moves. } \\
\text { 3.Appropriate time / movement but with some unnecessary movement. } \\
\text { 5. Good economy of movement. } \\
\text { 1----+----2----+-----3-----+----4----+----5 }\end{array}$ & $\mathrm{C}=$ \\
\hline $\begin{array}{l}\text { [29] Level of Independence } \\
\text { 1.He needs the constant assistance of the instructor } \\
\text { 3.He needs a moderate amount of assistance. } \\
\text { 5.No assistance required. } \\
\text { 1----+----2----+----3-----+---4----+---5 }\end{array}$ & $\mathrm{D}=$ \\
\hline $\begin{array}{l}\text { [30] Suture and Knotting Skills } \\
\text { 1.Unsafe suture or knotting. } \\
\text { 3.Suture and knotting normally safe but sometimes clumsy. } \\
\quad \text { 5.Suture and knot securely. } \\
\text { 1----+----2---+-----3----+----4----+---5 }\end{array}$ & $\mathrm{E}=$ \\
\hline $\begin{array}{l}{[31] \text { Totalglobalratingscale }} \\
{[A+B+C+D+E) / 25=}\end{array}$ & \\
\hline
\end{tabular}

END

[32] Procedure time (minutes)

[33] Coordinationbetweenthesurgeon and theassistant in animal

1. Incorrect

2. Correct
[34] Feedback between instructor and student?

1. Unsuitable

2. Suitable

[35] Debriefing?

1. No

2. Yes

[36] Instructor's comment and signature 
Table 5. Student feedback questionnaire.

FEEDBACK IN PRACTICE (STUDENT). It refers to the feedback during the development of the anastomosis. It aims to show how the interaction of the teacher with the student has been. This survey must be answered by the STUDENT after the end of the practice in the $\mathrm{HvV}$ (circle one of the numbers).

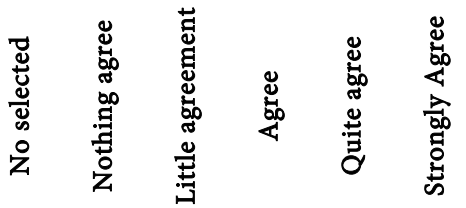

1) Indicates the name of the instructor

2) The instructor explains with order and clarity

3) The rhythm of the explanations allows you to follow the thread of the instruction

4) The prior theory fits with practical activity

5) The instructor emphasizes what he considers most important

6) When answering a question, it usually solves the doubt

7) Instructor encourages students to raise questions

8) The instructor uses resources (videos, internet, cards ...) that help to understand their knowledge

9) Encourage dialogue with students on the progress of practice

10) It has a receptive attitude and takes into account the opinion of the students.

11) The instructor tries to awaken in the student positive attitudes towards the task

12) The instructor treats students with respect

$\begin{array}{llllll}0 & 1 & 2 & 3 & 4 & 5 \\ 0 & 1 & 2 & 3 & 4 & 5 \\ 0 & 1 & 2 & 3 & 4 & 5 \\ 0 & 1 & 2 & 3 & 4 & 5 \\ 0 & 1 & 2 & 3 & 4 & 5 \\ 0 & 1 & 2 & 3 & 4 & 5 \\ 0 & 1 & 2 & 3 & 4 & 5 \\ 0 & 1 & 2 & 3 & 4 & 5 \\ 0 & 1 & 2 & 3 & 4 & 5 \\ 0 & 1 & 2 & 3 & 4 & 5 \\ 0 & 1 & 2 & 3 & 4 & 5 \\ 0 & 1 & 2 & 3 & 4 & 5\end{array}$

Autonomous Region of Cantabria, Spain (code: 2014.216), and informed consent was obtained from all participants.

\section{Results}

Analyzing the answers given by the group of experts of the Delphi study it was observed that according to them the most important quality parameters that the intestinal anastomosis should have are an adequate tension of the suture and a suitable distance between the points of the anastomosis. Also, according to them, the instructor's teaching experience and proper feedback between the participant and the instructor is also important. These assessments were taken into account to design the phases of the methodology.

After designing the phases of the methodology it was began with the learning sessions. Participants in the study were 15 women and 10 men who were grouped according to their level of experience. Thus $40 \%$ were beginners (10 first-year surgical residents), $40 \%$ trained (10 residents of the fourth and fifth year) and $20 \%$ formed the group of experts (5 surgeons senior). In the distribution there were no significant differences in sex or degree of experience in each group. To analyze the effectiveness of the teaching received, the quality parameters obtained by the three groups were compared in the first and fifth anastomosis. The beginners participants improved from $40 \%$ in eversion of the mucosal borders of the first anastomosis (CI-95\%: 16.8\% - 68.7\%) to 0\% (IC 95\%: 0.0\% -2 
7.8\%) in the fifth anastomosis. Loose suture tension improves from 10\% (IC 95\%: $0.5 \%-40.4 \%$ ) to $0 \%$ (IC $95 \%: 0.0 \%-27.8 \%$ ). The appropriate distance between points also improved from $40 \%$ to $80 \%$, while the leak remained at $20 \%$ (95\% CI: $5.7 \%-51.0 \%$ ) of the anastomosis performed, a percentage similar to that obtained by the experts in the fifth anastomosis (Figure 1).

The group of beginners was compared with the experts and in the fifth anastomosis, the first ones are equal to the second ones in the eversion (0\%), loose tension $(0 \%)$ and leakage (20\%) parameters. This gives an idea of the effective-

Eversion of anastomosis 1

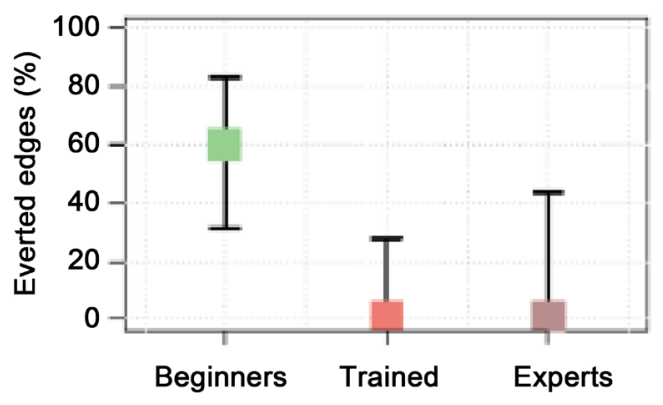

Level of Experience

Loosening of anastomosis 1

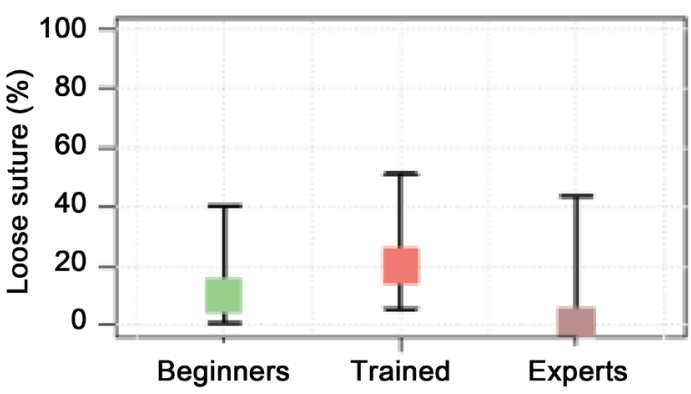

Level of Experience

Leakage of anastomosis 1

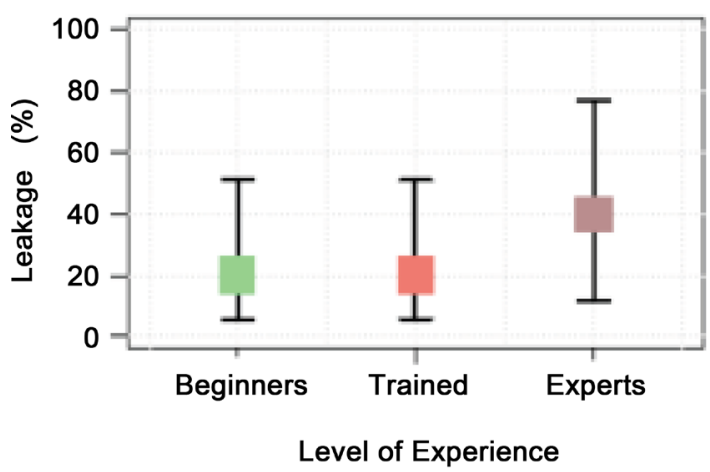

Eversion of anastomosis 5

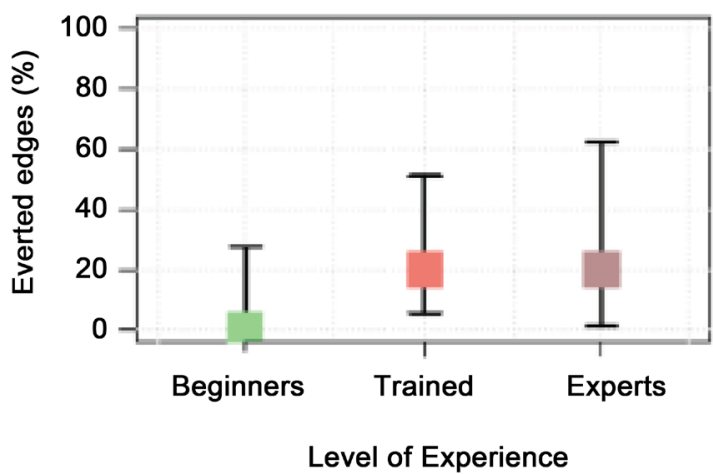

Loosening of anastomosis 5

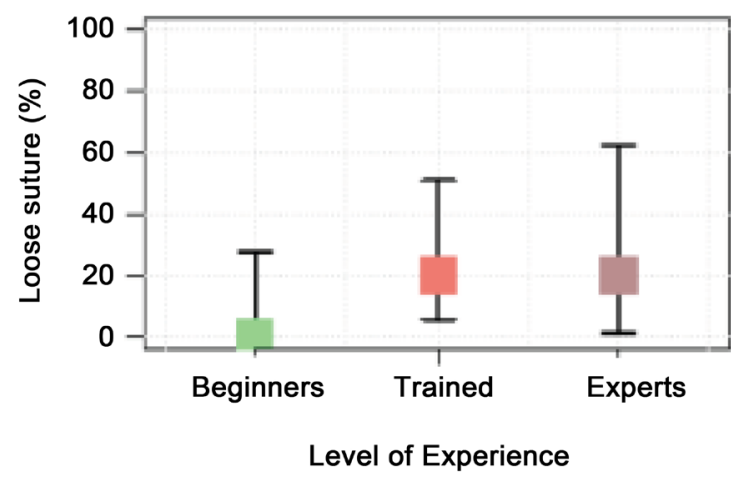

Leakage of anastomosis 5

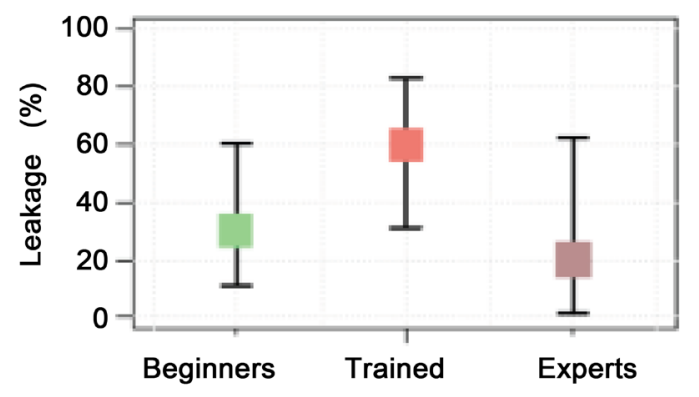

Level of Experience

Figure 1. Results of eversion, loosening and leakage of anastomosis. 
ness of the teaching received in the beginners participants.

In the TGRS test the beginners obtained a score of $1.7(\mathrm{SD}=0.29)$ and $3.5(\mathrm{SD}$ $=0.50)$ in the first and fifth anastomosis respectively. The experts' score was 4.2 $(\mathrm{SD}=0.09)$ and $4.6(\mathrm{SD}=0.15)$. Here also the improvement in the score of the test after five training sessions is observed, where the beginners failed to reach the experts' score but they improved significantly (Figure 2).

The time spent in the technical realization of the first anastomosis was 178 minutes ( $\mathrm{SD}=33.48$ ) on average in the begginners group. In the fifth anastomosis, the beginners took 94 minutes $(S D=20.38)$ compared to 43 minutes ( $\mathrm{SD}=7.16$ ), which took the experts to perform the fifth anastomosis. It is observed how the beginners have halved the time spent performing the anastomosis with only five training sessions (Figure 3 ).

\section{Test TGRS}

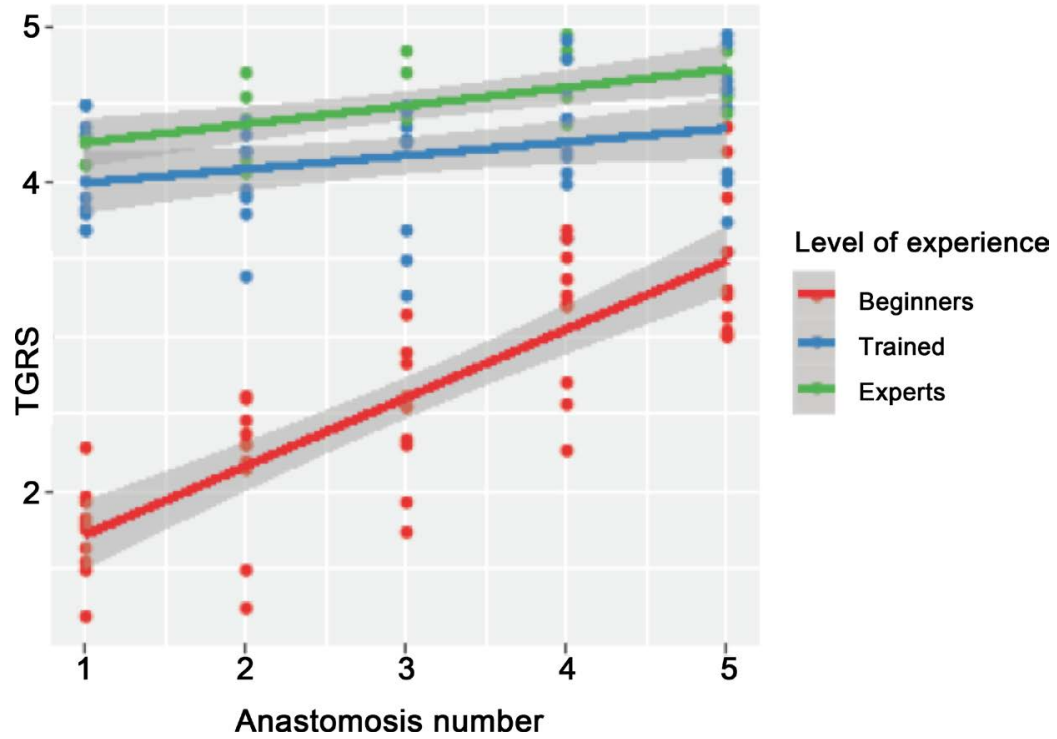

Figure 2. Assessment of the anastomosis according to the TGRS test.

\section{Time of the anastomosis}

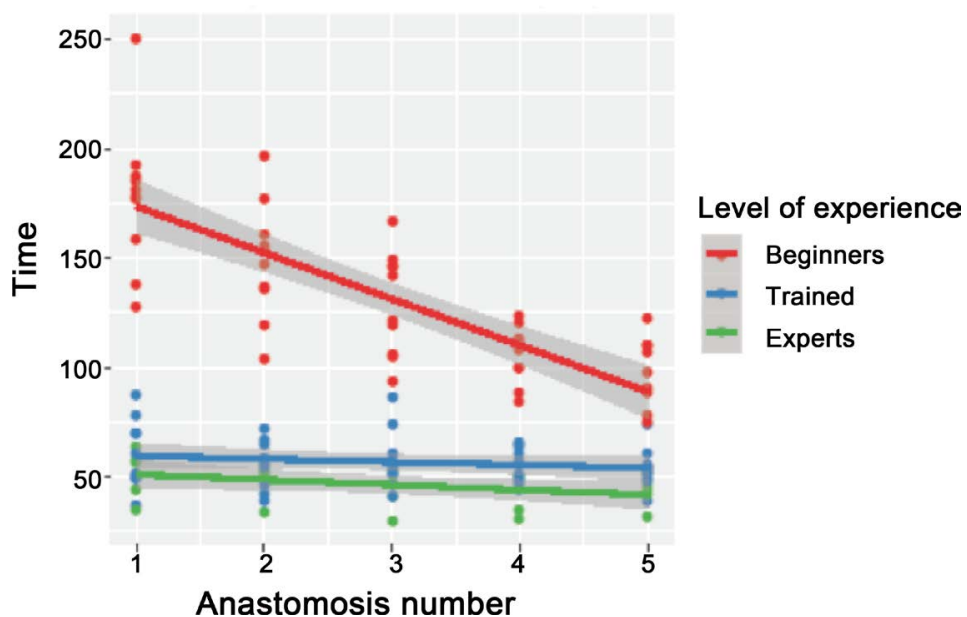

Figure 3. Time spent performing the anastomosis. 


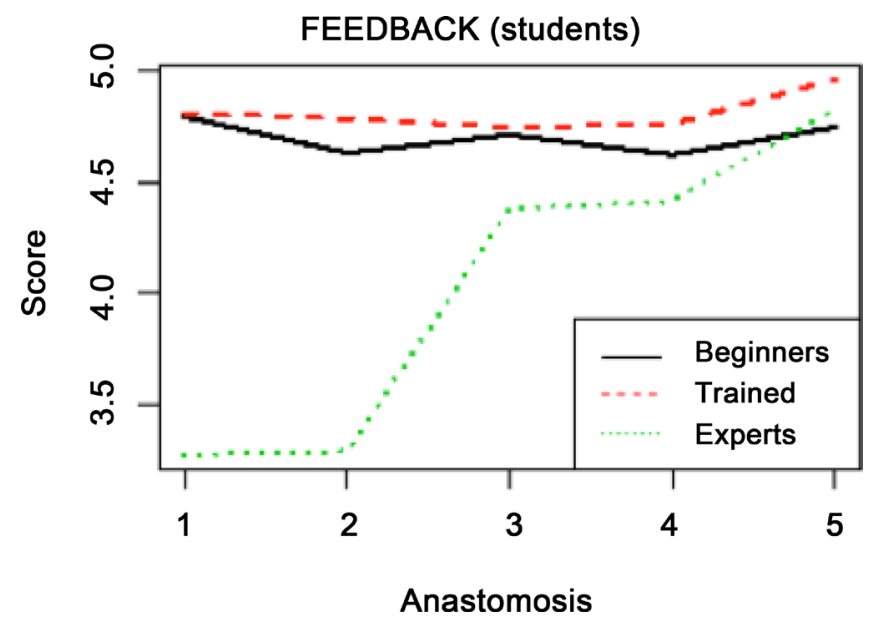

Figure 4. Assestment of feedback by students.

The learning curves of the beginners students were analyzed, relating the time spent in performing the anastomosis with the number of anastomosis performed. We observed that for each training session that the beginners perform, the time spent in an average of 21 minutes decreases.

The assessment of the feedback by the beginners participants was high throughout all the training sessions, recognizing in it their influence in the acquisition of learning (4.7/5). The assessment by the expert participants was low in the first anastomosis (3.3/5) to progressively improve and reach the score of the novices in the fifth anastomosis (4.8/5) (Figure 4).

The assessment of the feedback by the instructor was high in the sessions with the beginners participants (4.8/5), being lower in the sessions with the trained participants and experts (4.2/5 and 4.2/5) than is deduced that beginners were involved and used more feedback as a tool for improving learning.

Taking into account the quality parameters of the anastomosis, the perfect anastomosis has been defined as that which does not leak (F), which does not have an eversion of mucosal borders (E) and has an adequate tension of the suture ( $\mathrm{T}$ ) with a suitable distance between points (D). We do not know any tests described in the literature that quantitatively value the anastomosis performed in the simulation laboratories. Taking into account the results of this study, the FETD test was designed to assess the technical quality of the anastomosis performed with this methodology. Using a logistic regression model, the relationship of these parameters to the existence of leakage has been weighted, resulting in the FETD index whose formula is: FETD $=20-\left(10^{\star} \mathrm{F}+\right.$ $3^{*} \mathrm{E}+6^{*} \mathrm{~T}+1^{\star} \mathrm{D}$ ). With this formula the quality of the anastomosis performed during training can be quantitatively assessed. According to her the value of the perfect anastomosis is 20 .

The FETD test was applied to all the anastomosis performed with this methodology, observing how in the three groups most obtained a very high score between 15 and 20 points, showing the effectiveness of the methodology used (Figure 5). 


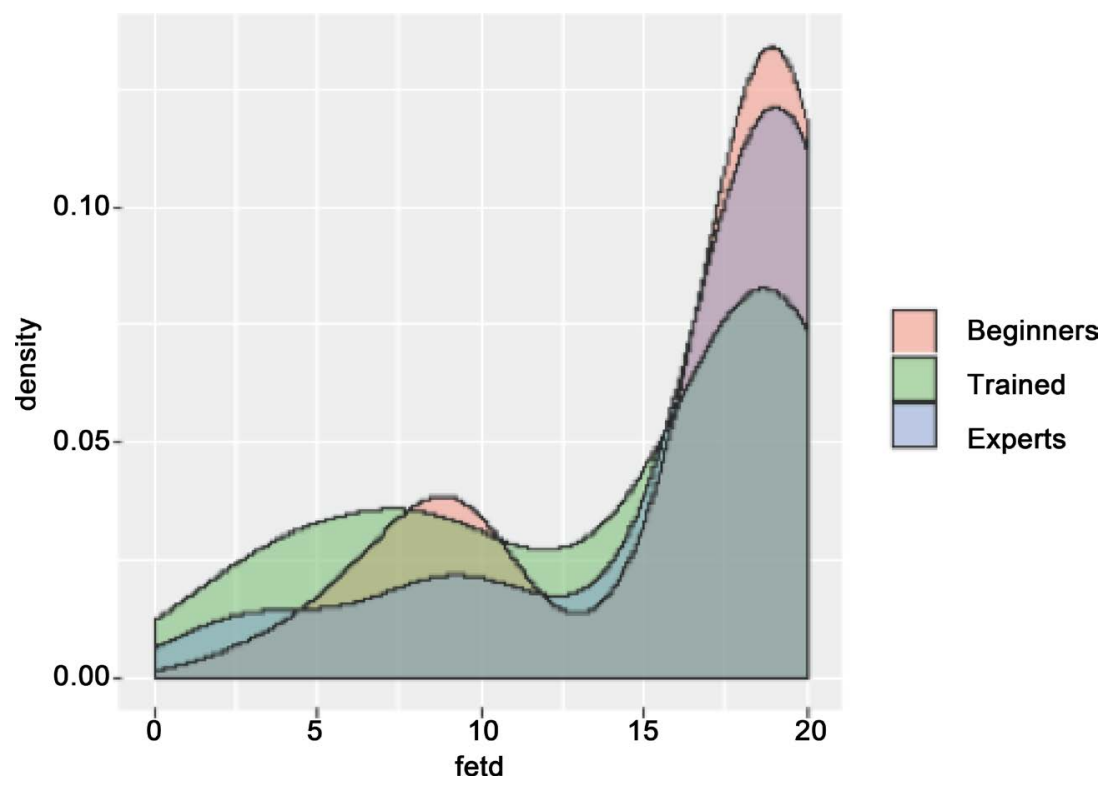

Figure 5. Assesment of anastomosis according to the test FETD.

If we compared the assessment of the anastomosis in the FETD test with the TGRS test, we observed that there is no correlation. Thus an anastomosis could be valued with a high score in the overall development of the operation and however be unsatisfactory according to the quality test [11].

\section{Discussion}

This new methodology has been designed trying to solve the multiple factors that hinder the teaching of technical skills in the hospital environment, proposes the turn towards a didactic system centered on the student, which implies their implementation in simulation laboratories where it is guaranteed The safety of the patient and is not influenced by the operating pressure of the operating room.

The methodology used in the teaching of technical skills must be flexible and must be adapted to the identity, reality, learning style and needs of each student. Not only must this information be acquired, it must also be developed [12].

In addition, the methodology should include an assessment that is part of the learning process and mold it [13]. In this methodology, the evaluation is carried out continuously, assessing both the achievements of the student and the instructor's teaching quality.

The objective of the methodology is that the student learn to perform the intestinal anastomosis correctly, so that in order to evaluate the effectiveness of the methodology it is necessary to evaluate the learning obtained by the students [14] and to evaluate this learning in the literature the quality of the anastomosis as well as the time taken to perform it [15] [16] [17].

Within the parameters of quality, it was evaluated not only the leakage pressure of the anastomosis but also the eversion of the mucosa, the tension of the suture or the distance between the points. As shown in the results with only five 
training sessions the beginners participants equate the experts with the quality parameters analyzed.

The criterion of leakage of the anastomosis was not identified by the Delphi experts as important in performing the anastomosis perhaps because in the real patient it is difficult to assess or because the actual anastomosis has vascularization and healing begins immediately. In this study for this quality parameter there is no improvement with training although the percentage of leakage in the beginners is similar to that obtained by the experts since the first anastomosis. According to the results obtained, the parameters associated with risk of leakage are firstly the loose tension of the suture and secondly the eversion of the mucosal edges. This finding differs from the opinion of the Delphi experts who consider the distance between the points as the main risk factor for the anastomosis. Thus the instructor during the teaching of the practice should emphasize the student's learning of an adequate realization of the tension of the suture and a correct invagination of the mucous edges.

The evaluation of the overall development of the operation is another instrument that is used to measure the competence that the student is acquiring. It has been shown a relationship between the evaluation obtained with this instrument and the performance in the operating room for the accomplishment of intestinal anastomoses [14] [18] [19]. The instrument used has been validated for intestinal anastomosis.

To carry out this assessment we recorded the care of the tissues, the development of the procedure, the time and movement employed, as well as the level of independence and the skills of suture and knotting.

In the first anastomosis the group of experts had the best evaluation.

When the same parameters were analyzed in the fifth anastomosis, it was observed that the group of beginners participants greatly improved the score, from 1.7 to 3.5 , approaching the 4.6 obtained by the experts in the fifth anastomosis. Thus it can be said that this instrument distinguishes between beginners and experts. In addition, the effectiveness of the methodology is also demonstrated by this instrument after five training sessions.

Another of the criteria identified by the Delphi experts as important for the teaching of anastomosis is prior knowledge before beginning the training [20].

The score in the prior knowledge test is directly related to the score obtained in the overall developmental test of the operation for the first anastomosis. Thus for each point in previous knowledge increases by 0.7 points the assessment in the TGRS test for the first anastomosis. In the fifth anastomosis it depends more on the previous experience of the participants than on the previous theoretical knowledge.

The time spent in the realization of the technique is another of the parameters that must be analyzed to evaluate the learning obtained. Authors like Hamad observed that after training the laparotomic anastomosis in an abdominal simulator, the time used was reduced by $43 \%$ to perform the fifth anastomosis [15]. 
In this study using a similar technique, an improvement in the time used by the beginners of a $48 \%$ in the fifth anastomosis with respect to the one performed in the first place. Participants improved at a rate of 21 minutes for each anastomosis performed.

Comparing with the experts, the beginners needed three times as much time as the experts to perform the first anastomosis. In the fifth anastomosis they only needed twice as much time.

Feedback is another of the phases also identified by the Delphi study experts. The students can learn the techniques after their vision in a video but it has been proven that this learning is inferior in time and quality to the learning that same student acquires when the teaching is given by an expert with a structured feedback [6]. It has been shown that feedback not only decreases the time required to perform the practice but also the number of sessions necessary to acquire the competence [7].

This methodology includes well-structured training feedback, where the instructor not only solves the doubts raised by the students but also tries to create a comfortable work environment to increase the student's motivation and decrease his level of anxiety.

The group of beginners participants was the one that used the most feedback to improve the learning of the technique. In addition it was also the group that valued him with greater punctuation as an enhancer element of the learning of the anastomosis (4.5/5 in the fifth anastomosis).

In the group of experts the feedback was lower than in the group of beginners perhaps because the experts have already completed their learning and also did so with a methodology where the feedback was not as structured as this or simply not used. Despite this, an improvement in the score is observed as the anastomosis is performed, progressively recognizing the value of the feedback as an enhancer element of the learning of the intestinal anastomosis (3.8/5 to 4.2/5 in the fifth anastomosis).

This study aims to value the new teaching methodology so that the instructor was always the same. However this may be one of the limitations of the study. We do not know if the results obtained with this methodology would be the same if it were imparted by another instructor with different teaching experience.

On the other hand, the level of ability and aptitude of the study participants has not been determined, which allows predicting individual differences in future learning situations and that could modify the learning curves by extending them in case of weakness in those skills [21].

As a strength it is possible to emphasize that the teaching methodology is developed in a simulation laboratory, which allows the student to train the technique as many times as necessary, without the operating pressure of the real operating room and without generating any risk in the patient's safety.

The phases included in the methodology have been designed based on the opinion of the experts, the characteristics of the learning of the technical skills in 
the human being, as well as taking into account the psychological theories of learning and the teaching models described in the literature.

Another aspect to emphasize of this work is to be able to describe the characteristics that must have an anastomosis to be considered perfect from a technical point of view. These characteristics can serve as a reference to evaluate the future anastomoses that the surgical apprentices perform in the simulation laboratories.

\section{Conclusion}

With this new learning methodology for an advanced surgical technique, such as the laparoscopic intestinal anastomosis, the provision of bibliographic and visual material to the participants before beginning the training of intestinal anastomosis improves the evaluation of the overall development of the operation. In the same way, it was observed that the beginners' participants, with only five training sessions, were able to perform the fifth anastomosis with quality criteria close to those of the experts. Feedback between the instructor and the participant during the training session diminishes the training sessions necessary to acquire the competence. The learning curves of the beginners' participants will serve as a reference for predicting the evolution of future beginners' participants when training with this methodology. The level of competence established by the experts will serve as a reference to determine the moment the participant acquired the competence. On the other hand this methodology allows individualizing the teaching to the specific learning needs of each participant.

\section{Conflict of Interest}

The authors have no conflict of interest to declare or financial disclosure. Valdecilla Virtual Hospital in Santander, Spain is a Simulation center with the mission of improving patient safety by means of expert training and development of healthcare professionals.

\section{References}

[1] Dudrick, S.J. (2011) Evolution of Surgical Education through the 20th Century into the 21st Century. Cirugía y Cirujanos, 79, 14-32.

[2] Nakayama, D.K. and Taylor, S.M. (2013) SESC Practice Committee Survey: Surgical Practice in the Duty-Hour Restriction Era. The American Surgeon, 79, 711-715.

[3] Zendejas, B., Brydges, R., Hamstra, S.J. and Cook, D.A. (2013) State of the Evidence on Simulation-Based Training for Laparoscopic Surgery: A Systematic Review. Annals of surgery, 257, 586-593. https://doi.org/10.1097/SLA.0b013e318288c40b

[4] Al-Kadi, A.S., Donnon, T., Oddone, P.E., Mitchell, P., Debru, E. and Church, N. (2012) The Effect of Simulation in Improving Students' Performance in Laparoscopic Surgery: A Meta-Analysis. Surgical Endoscopy, 26, 3215-3224. https://doi.org/10.1007/s00464-012-2327-z

[5] Ikonen, TS., Antikainen, T., Silvennoinen, M., Isojärvi, J., Mäkinen, E. and Scheinin, TM. (2012) Virtual Reality Simulator Training of Laparoscopic Cholecy- 
stectomies-A Systematic Review. Scandinavian Journal of surgery, 101, 5-12. https://doi.org/10.1177/145749691210100102

[6] O Connor, A., Schwaitzberg, S.D. and Cao, C.G.L. (2008) How Much Feedback Is Necessary for Learning to Suture? Surgical Endoscopy, 22, 1614-1619.

https://doi.org/10.1007/s00464-007-9645-6

[7] Bjerrum, F., Maagaard, M., Sorensen, J.L., Rifbjerg Larsen, C., Ringsted, C., Winkel, P., Ottesen, B. and Strandbygaard, J. (2015) Effect of Instructor Feedback on Skills Retention after Laparoscopic Simulator Training: Follow-Up of a Randomized Trial. Journal of Surgical Education, 72, 53-60. https://doi.org/10.1016/j.jsurg.2014.06.013

[8] Korndorffer, J.R., Arora, S., Sevdalis, N., Paige, J., McClusky, D.A. and Stefanidis, D. (2013) The American College of Surgeons/Association of Program Directors in Surgery National Skills Curriculum: Adoption Rate, Challenges and Strategies for Effective Implementation into Surgical Residency Programs. Surgery, 154, 13-20. https://doi.org/10.1016/j.surg.2013.04.061

[9] Martin, J.A., Regehr, G., Reznick, R., MacRae, H., Murnaghan, J., Hutchison, C. and Brown, M. (1997) Objective Structured Assessment of Technical Skill (OSATS) for Surgical Residents. British Journal of Surgery, 84, 273-278. https://doi.org/10.1002/bjs.1800840237

[10] The R Project for Statistical Computing (2015) http://www.r-project.org

[11] Ruiz Gomez, J.L. (2017) Evaluation of the Teaching Methodology of the Laparoscopic Intestinal Anastomosis in a Physical Simulator Supported by the Opinions of a Group of Experts Surveyed Using Delphi Methodology. University of Cantabria, Santander (España). http://hdl.handle.net/10803/402190

[12] García, P.P. (2009) Course of Initiation to University Teaching. Chapter 2. Teaching Methodology Appropriate to the New Structure of Higher Education. University of Granada, Granada.

[13] Bordas, M.I. and Carrera, F.A. (2001) Process-Focused Learning Assessment Strategies. Spanish Journal Pediatrics, 59, 25-48.

[14] Olson, T.P., Becker, Y.T., McDonald, R. and Gould, J. (2012) A Simulation-Based Curriculum Can Be Used to Teach Open Intestinal Anastomosis. The Journal of Surgical Research, 172, 53-58. http://hdl.handle.net/10803/402190

[15] Hamad, M.A., Mentges, B. and Buess, G. (2003) Laparoscopic Sutured Anastomosis of the Bowel. Surgical Endoscopy, 17, 1840-1844. https://doi.org/10.1007/s00464-002-8618-Z

[16] Gröne, J., Ritz, J.P., Stroux, A., Lehmann, K.S. and Lauscher, J.C. (2010) Measurable Learning Effects after a 1-Week Skills Course in Digestive Surgery. International Journal of Colorectal Disease, 25, 1133-1139. https://doi.org/10.1007/s00384-010-0976-8

[17] Shah, J., Munz, Y., Manson, J., Moorthy, K. and Darzi, A. (2006) Objective assessment of Small Bowel Anastomosis Skill in Trainee General Surgeons and Urologists. World Journal of Surgery, 30, 248-251. https://doi.org/10.1007/s00268-005-0074-1

[18] Varas, J., Mejía, R., Riquelme, A., Maluenda, F., Buckel, E., Salinas, J., Martínez, J., Aggarwal, R., Jarufe, N. and Boza, C. (2012) Significant Transfer of Surgical Skills Obtained with an Advanced Laparoscopic Training Program to a laparoscopic Jejunojejunostomy in a Live Porcine Model: Feasibility of Learning Advanced Laparoscopy in a General Surgery Residency. Surgical Endoscopy, 26, 3486-3494. https://doi.org/10.1007/s00464-012-2391-4 
[19] De Montbrun, S.L., Roberts, P.L., Lowry, A.C., Ault, G.T., Burnstein, M.J., Cataldo, P.A., et al. (2013) A Novel Approach to Assessing Technical Competence of Colorectal Surgery Residents: The Development and Evaluation of the Colorectal Objective Structured Assessment of Technical Skill (COSATS). Annals of Surgery, 258, 1001-1006. https://doi.org/10.1097/SLA.0b013e31829b32b8

[20] Glassman, D., Yiasemidou, M., Venkateswaran, B., Sivakumar, R., Majumder, S. and Biyani, C.S. (2016) A Multi-Specialty Surgical Course for Residents Transitioning from Early to Intermediate Training. International Journal of Medical Education, 7, 130-131. https://doi.org/10.5116/ijme.5708.e9ea

[21] Buckley, C.E., Kavanagh, D.O., Nugent, E., Ryan, D., Traynor, O.J. and Neary, P.C. (2014) The Impact of Aptitude on the Learning Curve for Laparoscopic Suturing. American Journal of Surgery, 207, 263-270.

https://doi.org/10.1016/j.amjsurg.2013.08.037

Submit or recommend next manuscript to SCIRP and we will provide best service for you:

Accepting pre-submission inquiries through Email, Facebook, LinkedIn, Twitter, etc. A wide selection of journals (inclusive of 9 subjects, more than 200 journals)

Providing 24-hour high-quality service

User-friendly online submission system

Fair and swift peer-review system

Efficient typesetting and proofreading procedure

Display of the result of downloads and visits, as well as the number of cited articles

Maximum dissemination of your research work

Submit your manuscript at: http://papersubmission.scirp.org/

Or contact ss@scirp.org 